\title{
Narrow-band imaging detects synchronous oropharyngeal squamous carcinoma during treatment of an early esophageal squamous cell carcinoma
}
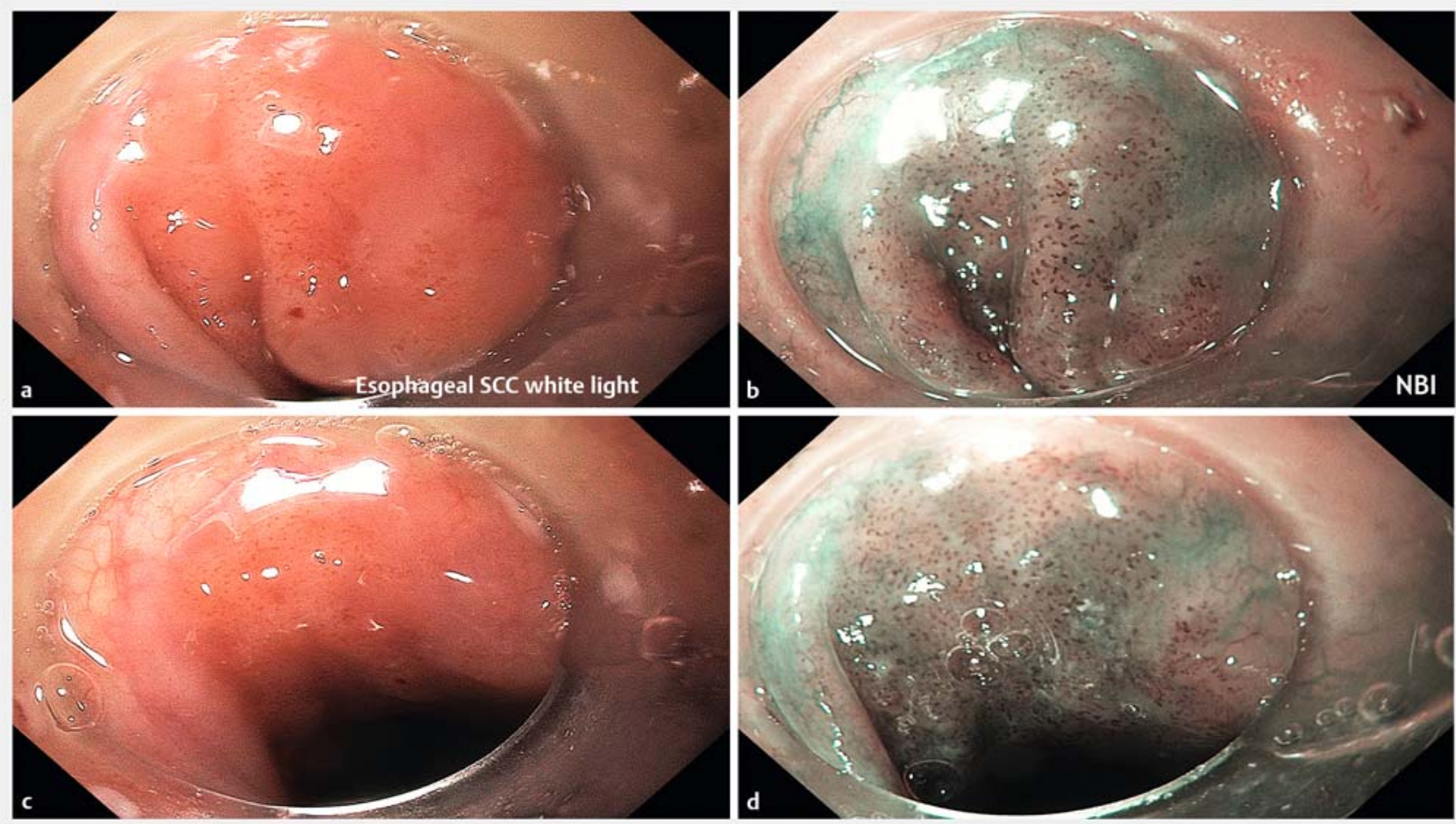

- Fig. 1 Esophageal epidermoid lesion. a,c Appearance with white-light imaging. b, d Appearance with narrow-band imaging.

Squamous cell carcinoma (SCC) can appear synchronously in the upper aerodigestive tract and in the esophagus by the mechanism of field cancerization, as tobacco and alcohol are both major risk factors for these lesions [1,2]. Narrowband imaging (NBI) and Lugol chromoendoscopy are the standard techniques for assessment of superficial esophageal lesions, although Lugol staining can lead to adverse events, such as mucosal irritation, allergic reactions, and aspiration, especially in the oropharyngeal area. NBI has proven to be superior to white-light imaging (WLI), with significantly higher diagnostic sensitivity in the detection of superficial mucosal lesions of the esophagus and pharynx [3], by showing altered intrapapillary capillary loop (IPCL) pattern [4].

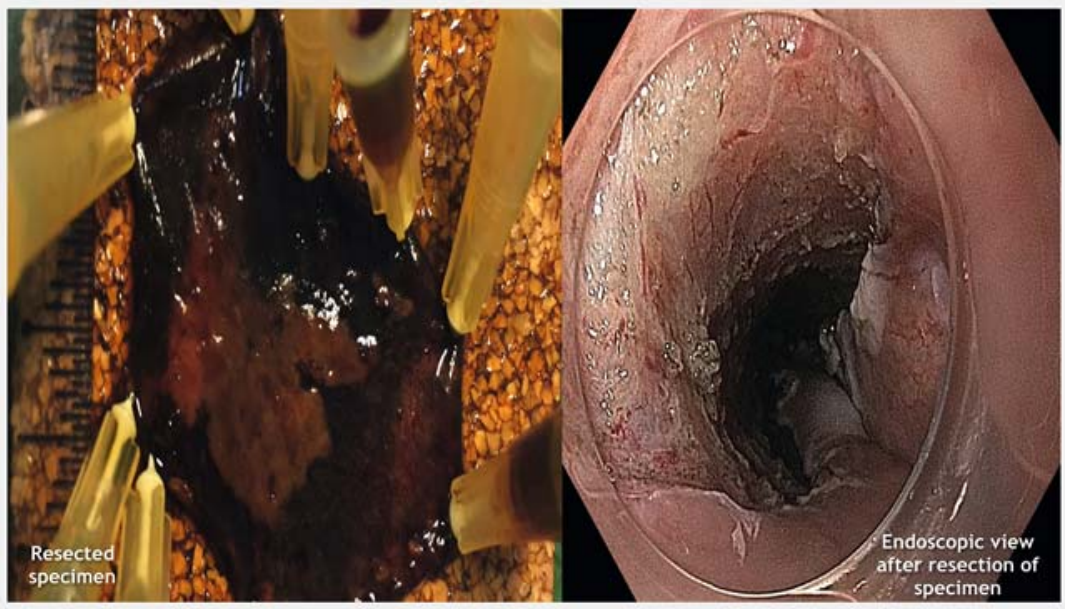

- Fig. 2 Resected specimen and endoscopic appearance after resection. 

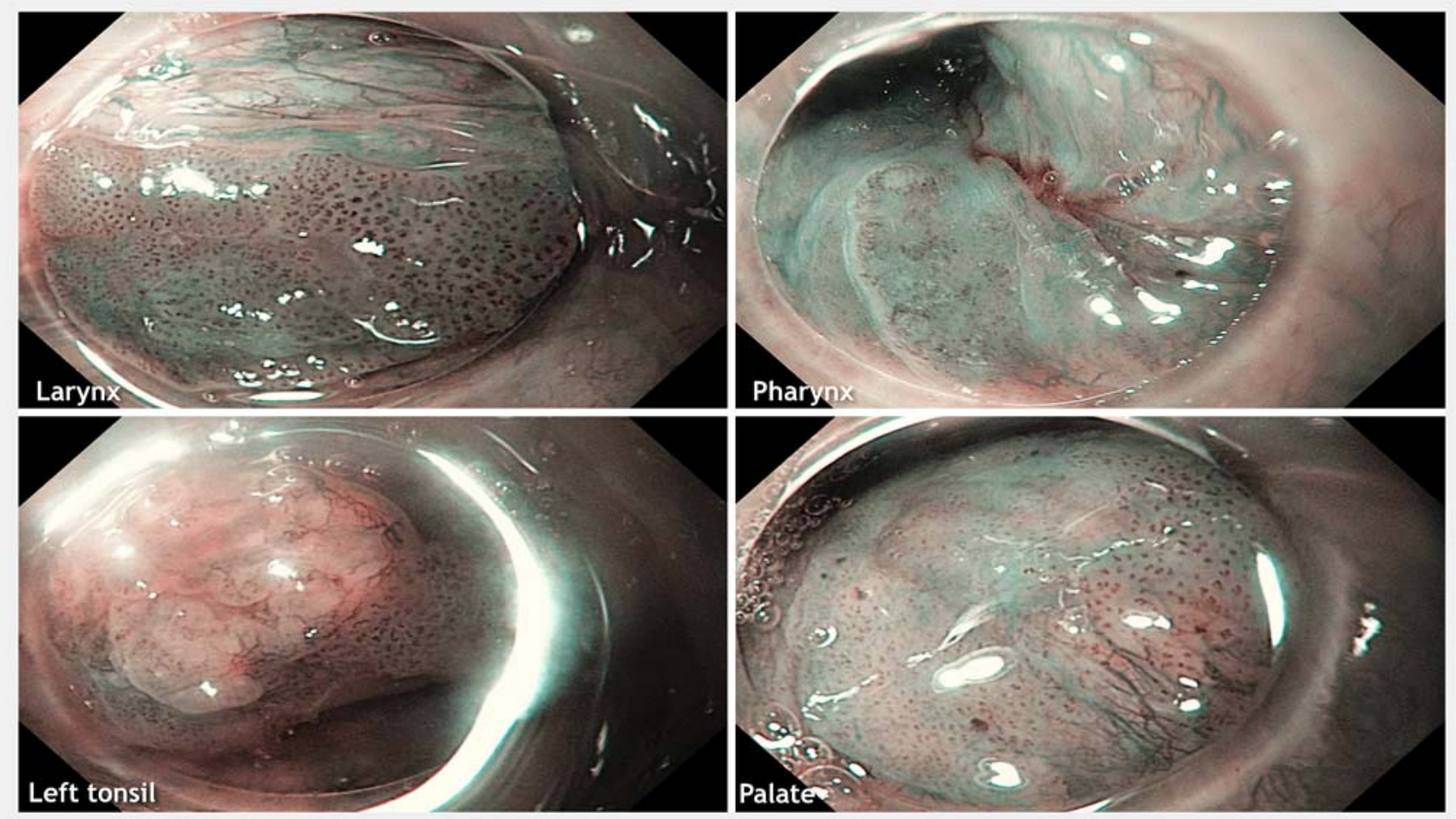

Fig. 3 Narrow-band imaging of lesions in pharynx, larynx, palate, and tonsil.

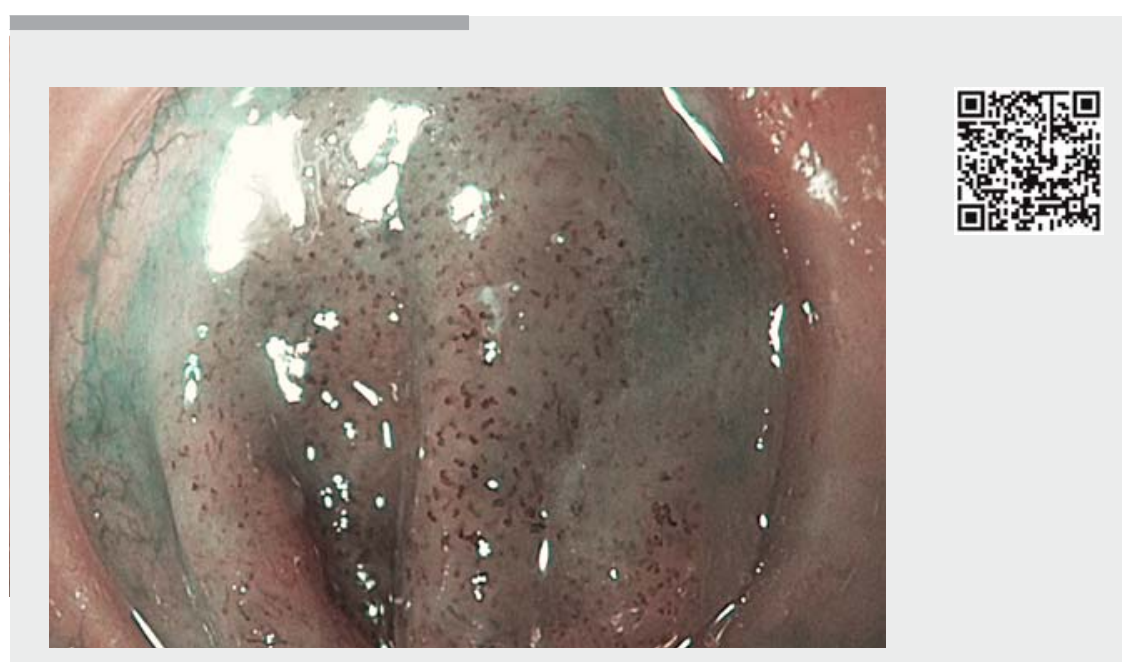

$\checkmark$ Video 1 Synchronous oropharyngeal squamous carcinoma detected by narrow-band imaging during treatment of an early esophageal squamous cell carcinoma.

We present here the case of a 58-yearold man who was referred for endoscopic evaluation of the esophagus.

Endoscopic examination found a reddish 2.5-cm anfractuous lesion ( $\triangleright$ Fig. 1 a) on the front wall of the proximal esophagus. NBI showed IPCL type B1 ( $\mathbf{F i g} . \mathbf{1}$ b). The margins were delineated and endoscopic
These lesions appeared typical with large IPCLs of various shapes (B1 type). Biopsies were taken from all lesions. The histology result from the resected esophageal specimen was in situ SCC without micro-invasion and R0 resection. Palate and tonsil biopsies also showed in situ SCC.

When an esophageal SCC lesion is found, the endoscopist should do a complete examination of the oropharyngeal area in order to detect synchronous lesions, which can be multiple in patients with long tobacco and alcohol use. NBI chromoendoscopy is safe, simple, and reproducible with no risk of aspiration, and should be used as a first-intention imaging technique.

Endoscopy_UCTN_Code_CCL_1AB_2pAB

\section{Competing interests}

formed, applying the tunnel and clip line technique ( Fig. 2) [5]. When withdrawing the endoscope using $\mathrm{NBI}$, multiple SCC lesions were found in the upper aerodigestive tract and oral cavity ( Video 1): on palate, right tonsil, pharynx, and left piriform sinus ( $\triangleright$ Fig.3).
Dr. Katzarov received a travel grant from the European Society of Gastrointestinal Endoscopy to join our team at Edouard Herriot Hospital for 4 months. 
The authors

Alexander Katzarov ${ }^{1,2}$, Alexandru Lupu ${ }^{1}$, Jérémie Jacques ${ }^{3}$, Jérôme Rivory ${ }^{1}$, Florian Rostain ${ }^{1}$, Thomas Walter ${ }^{1,4}$, Mathieu Pioche ${ }^{1,5}$

1 Department of Endoscopy and Gastroenterology, Pavillon L, Edouard Herriot Hospital, Lyon, France

2 Department of Gastroenterology and Hepatology, Military Medical Academy, Sofia, Bulgaria

3 Department of Endoscopy and Gastroenterology, Limoges University Hospital, Limoges, France

4 Digestive Oncology division, Pavillon E, Edouard Herriot Hospital, Lyon, France

5 Inserm U1032 LabTau, Lyon, France

Corresponding author

Mathieu Pioche, MD

Endoscopy Unit - Digestive Disease Department, Pavilion L - Edouard Herriot Hospital, 69437 Lyon Cedex, France Fax: +33-4-72110147

mathieu.pioche@chu-lyon.fr

\section{References}

[1] Ni XG, Zhang QQ, Zhu JQ et al. Hypopharyngeal cancer associated with synchronous oesophageal cancer: risk factors and benefits of image-enhanced endoscopic screening. J Laryngol Otol 2018; 132: 154 - 161

[2] Jaiswal G, Jaiswal S, Kumar R et al. Field cancerisation: concept and clinical implications in head and neck squamous cell carcinoma. J Exp Ther Oncol 2013; 10: 209-214

[3] Muto M, Minashi K, Yano T et al. Early detection of superficial squamous cell carcinoma in the head and neck region and esophagus by narrow band imaging: a multicenter randomized controlled trial. J Clin Oncol 2010; 28: $1566-1572$

[4] Oyama T, Inoue H, Arima M et al. Prediction of the invasion depth of superficial squamous cell carcinoma based on micro vessel morphology: magnifying endoscopic classification of the Japan Esophageal Society. Esophagus 2017; 14: 105-112

[5] Jacques J, Legros R, Rivory J et al. The "tunnel + clip" strategy standardized and facilitates oesophageal ESD procedures: a prospective, consecutive bi-centric study. Surg Endosc 2017; 31: $4838-4847$

\section{Bibliography}

DOI https://doi.org/10.1055/a-0640-2464

Published online: 3.7.2018

Endoscopy 2018; 50: E264-E266

(c) Georg Thieme Verlag KG

Stuttgart · New York

ISSN 0013-726X

\section{ENDOSCOPY E-VIDEOS}

https://eref.thieme.de/e-videos

回回 Endoscopy E-Videos is a free

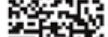

然: access online section, reporting on interesting cases and new

techniques in gastroenterological endoscopy. All papers include a high quality video and all contributions are freely accessible online.

This section has its own submission website at https://mc.manuscriptcentral.com/e-videos 